\title{
Strategic Choice on Transformation Mode of China's Resource-based Cities
}

\author{
Jinhuang Mao ${ }^{1}$ \\ ${ }^{1}$ School of Economics, Northwest University for Nationalities, Lanzhou, China \\ Correspondence: Jinhuang Mao, School of Economics, Northwest University for Nationalities, Lanzhou 730124, \\ China. E-mail: maojinhuang@126.com
}

Received: April 2, 2014

doi:10.5430/ijfr.v5n3p116

\author{
Accepted: May 1, 2014 \\ Online Published: June 18, 2014 \\ URL: http://dx.doi.org/10.5430/ijfr.v5n3p116
}

This work was supported by the Fundamental Research Funds for the Central Universities of Northwest University for Nationalities (Grant No: ZYZ2011016).

\begin{abstract}
The industrial structure of the resource-based cities is relatively single. The ability to withstand macroeconomic risk is relatively weak. And with the depletion of resources, the issue of the transformation of the resource-based cities is becoming more and more urgent. Currently, researches focus mainly on the selection and developing of the leading industries of the resource-based cities. This is the goal and direction of the transformation in the resource-based cities, which is to be solved in the researches. The key to the sustainable development of resource-based cities is to choose the appropriate mode based on the specific circumstances. Referring to the examples of some successful transformation and the existing theoretical results, the paper summarizes and introduces the transformation modes of the resource-based cities in China, which can provide a guidance to the sustainable development of the resource-based cities.
\end{abstract}

Keywords: resource-based cities, transformation, strategy choice

\section{Introduction}

The development of the resources city is based on the exploitation of natural resources. The feature of such cities is that the main industry is closely relative to the exploitation of natural resources. Under the planned economic system, the city is built completely in such a rush. The specialty of resources-based industry makes the transformation of industry as a certain stage of the development of resources-based city. A lot of studies have been done on the transformation of industry in the western countries. In China, due to the features of the natural resources and the certain background in the early independence, resources-based cities are located in everywhere and faced very serious recession, which took the high attention from governments and authorities. It is very important not only to the operation of the entirely national economics but also to social stability and unity whether the transformation of industry in resources-based cities is successful or not. Hence, it is much significant to study the transformation of industry in resources-based cities and to raise constructive strategy.

The ultimate aim of achieving industrial structure transition of resource-based cities is to accelerate urban economic development, encourage reasonable and sustainable resource utilization, protect ecological environment and speedup all-round social progress. In light of this objective, the strategic choice on transformation mode of resource- based cities should also take these four dimensions into comprehensive consideration.

\section{Lessons of the Transformation of the Resource-based Cities}

\subsection{Advanced Planning Is the Key to Success in the Transformation of Resource-based Cities}

The transformation of the resource-based cities is a complicated systematic project, involving all aspects of economy and the society. It takes a long time from the beginning of the transition implementation and policy formulation to the cultivation of the new leading industries, it cannot be finished overnight. Therefore, the resource-based cities must overcome the view of short term and instant success. Take the transformation of Ruhr, Germany and Lorraine, France as examples. Although the Government has provided huge financial support, it also took 30 years for a successful transformation. Practice has proved that, a resource-based city should have early and timely consideration of economic restructuring. The later the consideration is, the harder and more expensive the transformation will be. Therefore, to promote the transformation of resources cities, it is necessary to have advanced planning. When the 
resource-based city enters the stage of mature, it should begin to consider the economic transformation. The government should make appropriate development strategy and scientific transformation plan. In the stage of high-yielding and stable production, it should extract and accumulate capital for the transformation and develop non-resource -based industries to realize the timely implementation of economic restructuring.

\subsection{The Foundation of the Success in the Transformation of the Resource-based Cities Is to Develop New Leading} Industries

There is some resource-based urban transformation experience and practice in developed countries that can serve as good references and provide new ideas to us: One is to cultivate and develop new industries and restructure the economy. For example, the successful transformation of the Kyushu region, Japan, from coal industry to high-tech industrial zone ; Second, by extending the industrial chain resources and promoting the development of related industries as well as the implementation of pioneering transformation, such as the U.S. city of Houston, from a single oil industry to oil-related industries such as machinery, cement, steel, electricity, food and transportation, and then, in the opportunity of the National Aerospace distribution center, it developed the electronics, instrumentation and precision instruments industry.

\subsection{Government Leading Is a Major Driving Force for the Transformation of Resource-based Cities}

Ruhr, Lorraine and some other resource-based cities have achieved a successful transition in which the government plays a positive role. The governments have been leading the process of the transformation of resource-based cities. Government not only provides tremendous financial support, but also makes the relevant preferential policies in order to encourage and support the development of the small and medium enterprises, to utilize and attract foreign investment and to promote the rapid development of new industries and the tertiary industry; meanwhile the government also providing funds for the vocational training of workers and urban infrastructure construction, the improvement of the employee's skills and the economic development potential and so on. In the process of the transformation, the government can make appropriate legislation and industrial policy, support and guide the companies that have significant industry relevancy and that are of high-tech. It is also necessary for the government to make preferential policies about talent introduction, investment and tax to provide policy guidance to the transformation of the resource-based cities.

\section{Selection of the Modes for the Transformation of the Resource-based Cities}

The models of the transformation can be divided into different types, namely the industry continuation mode, the industry alternative mode and the industry continuation complex mode.

\subsection{Industry Continuation Mode}

The so-called industrial continuation mode is, on the basis of resource development, to develop the downstream processing industry and to establish the depth of processing and utilization of the resources industry group. Extractive industries are intermediate inputs of basic industries, the industry association is characterized by the significant forward linkage effects and the insignificant correlation effect, which is used to extends forward chain. The advantage of this mode lies in that it can fully use the local resources in the early time. In the meantime, the downstream industry has a significant correlation in the production, management and technology with the upstream industry, so that the difficulty of implementing of transformation is smaller. With the continuous development of downstream industries, the competitiveness and self-development capacity will gradually increase in the future. Even though the local resources are gradually depleted, they can also import resources from the external to maintain the lasting prosperity of the city. The outstanding problems of resource-based cities' industrial structure is that they are too dependent on the extractive industries while the downstream processing industry is weak and the out-put products are mainly cheap primary products, which not only makes the city's industrial structure single, but also caused a unreasonable national industrial structure.

\subsection{The Industry Alternative Mode}

The so-called substitution industrialization model is to establish a new industry group by using the accumulated capital, technology and talent, or with the help of external forces. It does not rely on the basic of existing resources, and the staff that engaged in resource development are transferred to the developing industry. This mode is undoubtedly the most thorough industrial transformation mode because it got rid of the dependence on existing resources. However, how to develop a competitive alternative industry group based on the extractive industries is the biggest challenge that the mode faces. This is because the company will gradually form certain styles of thinking and behaviors in the process of the business activities, namely the so-called dominant logic, when new business requirements of the new mode has conflict with the dominant logic, the company will easily makes mistakes in the management.

\subsection{The industrial Succeed Composite Mode}

In the so-called industrial succeed composite mode, a resource-based city not only employs some single model, but 
employs both of the two modes, namely, in the early stage of the transformation, the city employs the industry continuation mode, and the extractive industry gradually convert into processing industry. With the development of processing industry, the improvement of the urban functions and the continuous development of new industries, the city gradually evolved into a comprehensive city. In the early days of this transition mode, the city's leading industry gradually shifts from resource extractive industries to a leading industry group of processing industry. The gathering of a large number of processing enterprises in a certain area not only causes the agglomeration economy, but also benefits the spillover among the technology companies and promotes the development of technological advances and new industries. The original extractive industries of the resource-based cities are special and strong in technology, and the mobility of the employees are rather poor, the producing environment is isolated, the socialization level is low, mainly by internal self-supporting and it has little cooperative exchanges with other companies. The processing industries require the supporting mutual cooperation of different enterprises. The technical versatility and relation among the enterprises is strong. Compared to extractive industries, the processing industry has high employing mobility, easy new-technologies-spread between the upstream and downstream enterprises and enterprises of the same type. With the establishment and development of resource processing industry group, technology spillover and multiplier effects between enterprises will be increasingly strengthened, which can pave the road for the development of other industries. Resource-based cities should take advantage of this condition to promote the development of the new industries that do not rely on resources. In the process, the cities should take full advantage of the new investment opportunities in and abroad provided by the significant technological innovations and the appearance of the innovations group to promote the industrial upgrading and industrial alternatives and decrease the dependence on resources to achieve the city's industrial transformation.

\section{Conclusions}

Resource-based cities transformation is not just the adjustment of industrial structure, but also a comprehensive restructuring of economic, technical, social, cultural, which is a huge systematic project, which needs different transformation strategies according to different situations. For old cities where the resources have been depleted, various emergency measures should be taken to try to save the city form declination or recession and to achieve scientific transformation. For the potential resource-based cities, the transformation should be made during the heyday of their development and utilization of resources. Otherwise, the re-transformation of resource depletion and other difficulties will cost high. The potential resource-based cities should take the evade-transition strategy, which means, in the first stage of the mining, the problems that occurred in the old cities such as environment, employment, alternative industries and many other issues, should be considered first, full estimated and solved. The transformation of resource-based cities urgently need some special industrial policy, fiscal policy, environmental policy and protection, employment and social security policies, regional development and investment policies, particularly the need to increase aid to convert the industrial structure, to promote the development of non- resource industries, the establishment of aging abandoned mines converting funds, special funds resources city transformation and special workers social security funds, to raise the proportion of fiscal transfer payment, due to the development of training programs for workers in transition and re-employment programs, focused on solving the economic transformation of resource-based cities, social security and environmental sustainability and achieve full employment of labor. In terms of investment policy, the focus is to develop the private economy, to encourage the development of SMES. About the regional policy around the implementation of the western development strategy, establishment of the western resource-based cities "transformation zone" is needed. Around revitalizing the northeast old industrial base, the government should promote resource-based urban transformation and the transformation of old industrial bases in mutual interaction. Around central China, the government should promote resource-based city aggressively in order to realize the transformation.

\section{References}

Bradbury, J.H. (1981). Towards an alternative theory of resource-based town development. Economic Geography, 55(2), 147-166.

Burgess, E.W. (1925). The Growth of the City. Chicago University Press.

Button, K. J. (1982). Urban Economics: Theory and Policy. The MACMILLAN Press.

Clark, C. (1940). The Condition of Economic Progress. London.

J. H. Bradbury. (1979). Towards An Alternative Theory of Resource-based Town Development in Canada. Economic Geography, (2), 147-166.

Liu, Y., \& Zhang, A. (2010). Dynamic comparison on efficiencies of industrial structure of the typical coal cities in the central of China. Areal Research and Development, (1), 11-15.

Kuznets, S. (1985). Economic Growth of Nations: Total Output and Production Structure. The Commercial Press, Trans. Chang Xun, Beijing, pp. 111-112. 